\title{
Association of HNF1A gene variants and haplotypes with metabolic syndrome: a case-control study in the Tunisian population and a meta-analysis
}

Hamza Dallali ${ }^{1}$, Meriem Hechmi ${ }^{1,2}$, Imane Morjane ${ }^{3}$, Sahar Elouej ${ }^{1}$, Haifa Jmel ${ }^{1}$, Yosra Ben Halima ${ }^{1}$, Abdelmajid Abid ${ }^{1,4}$, Afef Bahlous ${ }^{5}$, Abdelhamid Barakat ${ }^{3}$, Henda Jamoussi ${ }^{1,4}$, Sonia Abdelhak ${ }^{1,6}$ and Rym Kefi ${ }^{1,6^{*}}$ (D)

\begin{abstract}
Background: Variants in the Hepatocyte Nuclear Factor 1 Alpha gene (HNF1A) are associated with lipoproteins levels and type 2 diabetes. In this study, we aimed to assess the association of HNF1A gene and haplotypes with the metabolic syndrome (MetS) and its components through an association study in the Tunisian population as well as by a meta-analysis.

Methods: A total of 594 Tunisian individuals were genotyped for three variants (rs1 169288, rs2464196 and rs735396) located in HNF1A gene using KASPar technology. Statistical analyses were performed with R software. The association was furthermore evaluated through a meta-analysis of our results with those obtained in a Moroccan population.

Results: Our results showed no association between HNF1A variants and MetS in the Tunisian population. However, a significant association was observed between the variant rs735396 and a higher waist circumference. The stratified analysis according to the sex highlighted a significant association between the variant rs 1169288 and high cholesterol levels only in women. Similarly, Haplotype analysis showed an association between the HNF1A minor haplotype and high total cholesterol mainly in women. Finally, our meta-analysis showed no association between HNF1A variants and MetS.
\end{abstract}

Conclusions: Our findings exclude the involvement of the three HNF1A variants rs 1169288 , rs2464196 and rs735396 in the susceptibility to MetS in our studied Tunisian population but emphasize the role of these variants in the cholesterol homeostasis with sex-specific differences, which may serve to rise clinical consideration to early statin therapy in women carrying these genetic variants.

Keywords: Hepatocyte Nuclear Factor-1-Alpha gene, Metabolic disorders, Lipids, SNP, Haplotype, North Africa

*Correspondence: rym.kefi@pasteur.utm.tn; Rym.Kefi@pasteur.tn ${ }^{1}$ Laboratory of Biomedical Genomics and Oncogenetics, Institut Pasteur in Tunis, BP 74, 13 Place Pasteur, Belvedere, 1002 Tunis, Tunisia Full list of author information is available at the end of the article

\section{Introduction}

Metabolic syndrome (MetS) is characterized by the clustering of risk factors for heart disease and type 2 diabetes (T2D). These risk factors include central obesity, hyperglycemia, hypertension, and altered lipid profile $[1,2]$.

The prevalence of MetS has reached levels comprised between 20 and $40 \%$ across populations in the last two original author(s) and the source, provide a link to the Creative Commons licence, and indicate if changes were made. The images or other third party material in this article are included in the article's Creative Commons licence, unless indicated otherwise in a credit line to the material. If material is not included in the article's Creative Commons licence and your intended use is not permitted by statutory regulation or exceeds the permitted use, you will need to obtain permission directly from the copyright holder. To view a copy of this licence, visit http://creativecommons.org/licenses/by/4.0/. The Creative Commons Public Domain Dedication waiver (http://creativeco mmons.org/publicdomain/zero/1.0/) applies to the data made available in this article, unless otherwise stated in a credit line to the data. 
decades [3]. In Tunisia, the prevalence is $30 \%$ of the population according to the last epidemiological study carried out in 2013 [4]. Consequently, MetS represents a heavy burden on the human public health system both in developing and developed countries. MetS is a complex multifactorial syndrome. Environmental factors such as low physical activity and hypercaloric diet are potential determinants of MetS $[4,5]$. The genetic component is also crucial since MetS incidence is significantly higher in individuals with family history [6, 7].

Genome wide association studies (GWAS) have identified loci associated with MetS as an overall entity, or with some of its phenotypic traits or its complications $[8,9]$. In 2009, Kathiresan et al. conducted genome wide association screens in 19,840 individuals and replication in up to 20,623 individuals in order to investigate the polygenic basis of the dyslipidemia traits. They highlighted single nucleotide polymorphisms (SNPs) in 30 loci associated with lipoproteins and triglycerides levels, of which 11 loci reaching genome wide significance $\left(\mathrm{p}<5.10^{-8}\right)$ for the first time. These 11 loci include genes such as Hepatocyte Nuclear Factor 1 Alpha (HNF1A) [10].

HNF1A (MIM*142410) is located on chromosome $12 \mathrm{q} 24.2$ and counts 10 exons. The protein encoded by this gene is a transcription factor required for the expression of at least 222 liver-specific genes that are essential in the carbohydrate synthesis and storage as well as in lipid metabolism (synthesis of cholesterol and lipoproteins) [11]. Defects in $H N F 1 A$ gene are known to cause maturity onset diabetes of the young type 3 (MIM\#600496). This form of diabetes has an autosomal dominant inheritance, and it is characterized by severe hyperglycemia caused by beta cells insulin secretion deficit, and an age of onset generally younger than 25 years [12].

Some studies were carried out to test the association of $H N F 1 A$ gene variants with metabolic disorders. In 2011, Avery et al. conducted a GWAS including 19,486 European American and 6287 African American and they detected the association of a $H N F 1 A$ variant with a phenotypic cluster consisting of atherogenic dyslipidemia, vascular inflammation and prothombotic state [9]. Other studies have detected associations of HNF1A variants with some MetS components including altered lipid profile and its complications in different populations [13-22].

Among these reported variants, we selected for our study three SNPs: rs1169288 located in the exon 1 also known as I27L, rs2464196 located in the exon 7 also called S487N, and rs735396 located in the intron 9.

The main goals of the present study are: (1) to investigate the association of $H N F 1 A$ gene variants (rs1169288, rs2464196 and rs735396) and haplotypes with the susceptibility to MetS and its components in the Tunisian population, (2) to perform a meta-analysis of the association between $H N F 1 A$ variants and MetS. Our study is the third to test association of $H N F 1 A$ variants with MetS, and it includes the first meta-analysis to date of this association. These variants were previously associated with MetS, altered lipoproteins levels and type 2 diabetes [15, $16,18,20,23,24]$.

\section{Materials and methods \\ Study subjects}

This study is conducted in the frame of MEDIGENE project, that was approved by the Ethical committee of Institut Pasteur in Tunis (Reference IPT/LR11-05/Etude 04/2013) [25]. A total of 594 participants (299 controls and 295 MetS patients), aged between 35 and 75 years, were recruited and clinically characterized as previously described [26, 27].

\section{Genetic analysis}

Genomic DNA was isolated from the whole blood. Genotyping of SNPs was performed by KASPar ${ }^{\circledR}$ technology (KBioscience, UK) using the LightCycler $480^{\circledR}$ system (Roche Diagnostics, Switzerland) [28]. A random of 10\% sample set was re-tested with the same method to confirm genotype accuracy.

\section{Statistical analysis}

The power analysis of the case-control study was performed using PS: Power and Sample Size Calculations software version (3.1.2) [29].

The measured clinical features were expressed as means \pm standard deviations, and differences between groups were assessed with Student Test.

The Hardy Weinberg equilibrium (HWE) was checked for each of the genotyped SNPs. Allelic and genotypic frequencies for the three SNPs were calculated in the studied population. The associations of the genotyped SNPs with MetS were estimated using multivariate logistic regression model after adjustment for age, sex and body mass index (BMI). Linear regression analysis was performed to identify the associations between the variants and the measured quantitative traits. The association tests were performed under three different genetic models: codominant, dominant and recessive models of inheritance. Results were expressed as nominal p-values, odds ratios (OR), and 95\% confidence intervals (CI). A p-value $<0.05$ was considered statistically significant for statistical tests. The p-values were corrected with the Bonferroni correction by multiplying with the number of comparisons. Statistical analyses were performed using SNPassoc R package [30].

Linkage disequilibrium (LD) statistics was computed using $\mathrm{r}^{2}$ coefficient by Haploview software (version 4.2) 
[31]. Haplotype frequencies and associations with MetS were estimated using PLINK software (version 1.07) [32]. In addition, we explored the haplotype associations with the measured quantitative traits using a generalized linear model from the haplo.score function incorporated in the haplo.stats R package [33].

\section{Meta-analysis}

Relevant studies, evaluating the associations between HNF1A polymorphisms and MetS, were identified by searching HuGe navigator (https://phgkb.cdc.gov/ PHGKB/hNHome.action) and PubMed (https://www. ncbi.nlm.nih.gov/pubmed/) databases. We used different combinations of the following keywords: "HNF1A", "metabolic syndrome", "association" and "polymorphism". The references of retrieved studies were inspected to identify any other relevant studies.

Association studies included in our meta-analysis had to meet the following criteria: (1) the MetS was defined according to the International Diabetes Federation criteria; (2) evaluation of association of HNF1A polymorphisms with MetS in at least two studies; (3) use of a case-control design; (4) the given information was sufficient to calculate the pooled odds ratio (OR), either a contingency table containing the number of controls and MetS cases with the different genotypes levels of the studied polymorphisms, or the raw genotyping data.

Statistical heterogeneity across studies was evaluated by using the chi-square based Q test and the $\mathrm{I}^{2}$ statistics [34]. If there is no heterogeneity across studies $(Q$ test $\mathrm{p}$-value $>0.1$ or $\mathrm{I}^{2}<50 \%$ ), the fixed effects model of Mantel-Haenszel was conducted for the meta-analysis [35]. Otherwise, the random effects model of DerSimonian and Laird was used [36].

Statistical tests were performed using GWAMA software (version 2.2.2) [37]. The R library "rmeta" was used to draw the forest plots [38]. Publication bias was checked by using Begg's test computed with the metaphor R package [39].

\section{Results}

\section{Characteristics of the studied population}

The biochemical and clinical data of the studied population are presented in Table 1.

The BMI, WC, TG, low density lipoprotein cholesterol (LDL), FPG, diastolic and systolic blood pressure were significantly higher in MetS patients compared to controls. An opposite result was observed only with HDL levels.

\section{Association with MetS}

Based on the minor allele frequency of the genotyped SNPs in EXAC database (http://exac.broadinstitute.org/),
Table 1 Clinical and biochemical characteristics of the studied Tunisian population

\begin{tabular}{lccc}
\hline & Controls $(\mathbf{n}=\mathbf{2 9 9})$ & Mets $(\mathbf{n}=\mathbf{2 9 5})$ & p-value \\
\hline Age (years) & $52.56 \pm 10.09$ & $56.58 \pm 8.56$ & $<0.001$ \\
WC $(\mathrm{cm})$ & $97.07 \pm 11.87$ & $106.50 \pm 9.94$ & $<0.001$ \\
BMI $\left(\mathrm{Kg} / \mathrm{m}^{2}\right)$ & $28.41 \pm 4.83$ & $31.53 \pm 5.12$ & $<0.001$ \\
FPG $(\mathrm{mmol} / \mathrm{l})$ & $6.13 \pm 2.51$ & $9.52 \pm 4.28$ & $<0.001$ \\
TC $(\mathrm{mmol} / \mathrm{l})$ & $5.08 \pm 0.92$ & $5.16 \pm 1.01$ & 0.28 \\
HDL $(\mathrm{mmol} / \mathrm{l})$ & $1.48 \pm 0.41$ & $1.13 \pm 0.34$ & $<0.001$ \\
LDL $(\mathrm{mmol} / \mathrm{l})$ & $3.12 \pm 0.89$ & $3.16 \pm 1.34$ & 0.049 \\
TG $(\mathrm{mmol} / \mathrm{l})$ & $1.29 \pm 0.56$ & $2.02 \pm 0.93$ & $<0.001$ \\
DBP $(\mathrm{mmHg})$ & $7.74 \pm 1.26$ & $8.35 \pm 1.40$ & $<0.001$ \\
SBP $(\mathrm{mmHg})$ & $13.20 \pm 1.97$ & $14.6 \pm 2.1$ & $<0.001$ \\
\hline
\end{tabular}

$B M I$ Body Mass Index, DBP diastolic blood pressure, FPG fasting plasma glucose, $H D L$ high density lipoprotein cholesterol, $L D L$ low density lipoprotein cholesterol, SBP systolic blood pressure, TC total cholesterol, TG triglycerides, WC waist circumference. Data are presented as mean \pm standard deviation (SD)

the power analysis demonstrated that our study sample size (299 controls/295 cases) is sufficient to detect odds ratios $\simeq 1.6,1.603$ and 1.592 for rs1169288, rs2464196 and rs 735396 respectively with $80 \%$ of power at $\mathrm{p}<0.05$.

Genotypic success rates were $99.32 \%$ for rs 1169288 , $100 \%$ for rs 2464196 and $99.5 \%$ for rs735396. The genotypic and allelic distribution of HNF1A variants (rs1169288, rs2464196 and rs735396) and the result of the association with MetS are shown in the Additional File 1. The three genotyped SNPs did not deviate from HWE, and their genotype distributions are not significantly different between MetS patients and controls in our Tunisian cohort.

In addition, we performed an association analysis after stratification of the studied population according to the sex. Our results showed no association with MetS neither for men nor for women (Additional file 2).

The whole sample was stratified into Northern and Southern groups in order to investigate the impact of the geographic origin on the genotype distribution of $H N F 1 A$ variants. Association analyses of the three $H N F 1 A$ variants with MetS performed for each group separately showed no significant associations under any genotypic model (Additional file 3). Furthermore, we did not find any significant difference in the distribution of $H N F 1 A$ genotypes after stratification of the whole sample according to the sex and to the geographic origin (Additional file 4).

\section{Association with quantitative traits}

The association analyses results of the HNF1A variants with different quantitative traits are shown in Table 2. We applied the recessive model since it has the lowest Akaike Information Criterion (AIC) value as shown in the additional file 1 . 
Table 2 Association of HNF1A variants with metabolic syndrome traits in the studied Tunisian population

\begin{tabular}{|c|c|c|c|c|c|c|c|c|c|c|c|c|}
\hline & \multicolumn{4}{|c|}{ rs1169288 } & \multicolumn{4}{|c|}{ rs2464196 } & \multicolumn{4}{|c|}{ rs735396 } \\
\hline & $\mathrm{AA}+\mathrm{AC}$ & $\mathrm{CC}$ & $p$-value & p-value* & $\mathrm{GG}+\mathrm{GA}$ & $A A$ & $p$-value & p-value* & $\mathrm{TT}+\mathrm{TC}$ & CC & $p$-value & p-value* \\
\hline WC (cm) & 101.6 & 102.3 & 0.65 & 1 & 101.6 & 105.3 & $0.035^{\mathrm{a}}$ & 0.105 & 101.5 & 104.3 & $0.013^{\mathrm{a}}$ & $0.039^{\mathrm{a}}$ \\
\hline BMI $\left(\mathrm{kg} / \mathrm{m}^{2}\right)$ & 30.05 & 30.17 & 0.99 & 1 & 29.93 & 30.68 & 0.1 & 0.3 & 29.94 & 30.35 & 0.35 & 1 \\
\hline FPG (mmol/l) & 7.81 & 8.68 & 0.1 & 0.3 & 7.8 & 8.36 & 0.47 & 1 & 7.9 & 7.88 & 0.85 & 1 \\
\hline SBP (mmHg) & 14.01 & 13.81 & 0.48 & 1 & 13.95 & 14.11 & 0.62 & 1 & 13.98 & 13.95 & 0.72 & 1 \\
\hline $\mathrm{DBP}(\mathrm{mmHg})$ & 8.08 & 8.08 & 0.99 & 1 & 8.07 & 8.08 & 0.61 & 1 & 8.11 & 7.97 & 0.27 & 0.81 \\
\hline TC (mmol/l) & 5.09 & 5.31 & 0.056 & 0.168 & 5.08 & 5.30 & 0.056 & 0.168 & 5.11 & 5.13 & 0.83 & 1 \\
\hline $\mathrm{HDL}(\mathrm{mmol} / \mathrm{l})$ & 1.30 & 1.38 & 0.07 & 0.21 & 1.3 & 1.37 & $0.037^{a}$ & 0.111 & 1.29 & 1.36 & 0.08 & 0.24 \\
\hline LDL (mmol/l) & 3.24 & 3.31 & 0.61 & 1 & 3.23 & 3.34 & 0.45 & 1 & 3.24 & 3.25 & 0.9 & 1 \\
\hline TG $(\mathrm{mmol} / \mathrm{l})$ & 1.66 & 1.76 & 0.5 & 1 & 1.66 & 1.71 & 0.96 & 1 & 1.66 & 1.69 & 0.8 & 1 \\
\hline
\end{tabular}

Data are presented as means. Linear regression, adjusted for age, sex and BMI, was used to assess genotype phenotype correlations under the recessive model of inheritance

$B M I$ Body Mass Index, DBP diastolic blood pressure, FPG fasting plasma glucose, $H D L$ high density lipoprotein cholesterol, $L D L$ low density lipoprotein cholesterol, SBP systolic blood pressure, TC total cholesterol, TG Triglycerides, WC waist circumference

a Indicated a significant result

p-value*: p-values after Bonferroni correction

For the Bonferroni correction, $p$-values were multiplied by 3 (the number of SNPs in our study)

Calculations were performed using SNPassoc $\mathrm{R}$ package

The carriers of two copies of the rs735396 minor allele had significantly higher WC than the carriers of the reference and the heterozygous genotypes. This association remained significant after Bonferroni correction ( $\mathrm{p}$-value $=0.039$ ).

The genotype distribution of the variant rs2464196 showed a significant difference between controls and MetS patients for WC (p-value $=0.035)$ and HDL levels $(p=0.037)$ after adjustment for age, sex and BMI. However, these associations were lost after Bonferroni correction. Regarding the variant rs1169288, we did not find any significant association with any trait of the MetS.

We investigated also the association of the three $H N F 1 A$ variants with quantitative traits in the group of women and men. Our results showed that the female carriers of the rs1169288 CC minor genotype had higher cholesterol levels (mean $=5.58 \mathrm{mmol} / \mathrm{l}$ ) compared to the female carriers of AA+ AC genotypes $($ mean $=5.14 \mathrm{mmol} / \mathrm{l})$. This association remains significant after Bonferroni correction (Additional file 5).

\section{Haplotype association analysis}

The analysis of LD pattern showed low to medium correlations between the three genotyped SNPs in our study $\left(0.38<=\mathrm{r}^{2}<=0.68\right)$ (Fig. 1).

The haplotype analysis of the three genotyped SNPs (rs1169288, rs2464196 and rs735396) showed no significant association with MetS neither in total cohort nor in stratified groups according to the sex (Additional files 6 \& 7). However, a significant association was found between

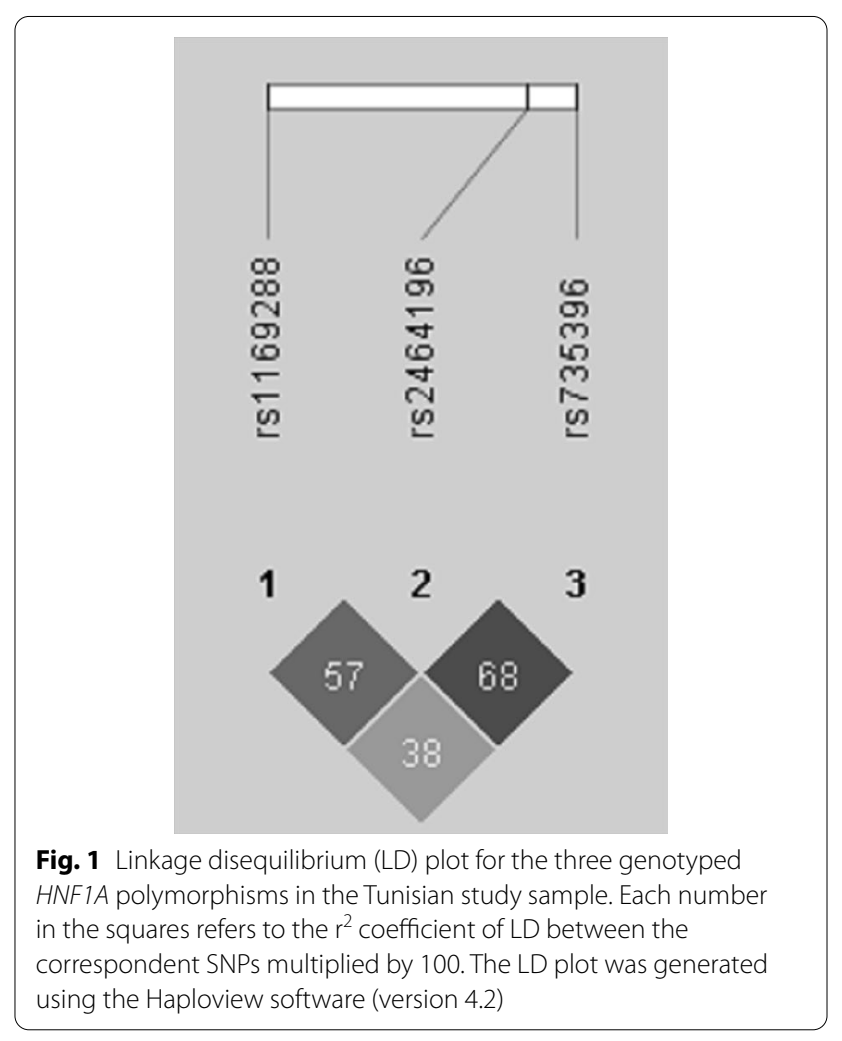

the minor haplotype $\mathrm{CAC}$ and higher cholesterol levels in the women group (Additional file 8). 


\section{Meta-analysis}

Following our inclusion criteria, we identified only one study investigating the association of three HNF1A polymorphisms (rs1169288, rs2464196, rs735396) with the Mets in the Moroccan population (Table 3).

The study conducted by Morjane et al. in the Moroccan population reported an association of rs1169288 and rs2464196 with the risk of MetS under codominant and dominant genetic models, which was not the case in the study conducted in our Tunisian cohort. Regarding rs735396, the two studies suggested the absence of its association with MetS in both populations. Begg's test showed that there is no publication bias for the three polymorphisms (all $\mathrm{P}>0.05$ ).

The meta-analysis results of both fixed and random effects models are summarized in Table 4. There was no significant association between any of the three studied $H N F 1 A$ polymorphisms and the MetS risk.

The results of the association of the HNF1A polymorphisms with MetS after stratification following the sex in the Moroccan study sample are available in the Additional File 9. The meta-analysis stratified by the sex showed a significant association of rs1169288 with MetS only in the women group, under the codominant and dominant genetic models (Additional file 10 \& Fig. 2). This signal was found in the fixed effects model. However, the Cochrane's $\mathrm{Q}$ test $\mathrm{p}$-value and $\mathrm{I}^{2}$ values indicate the presence of significant heterogeneity between the findings of the two studies for this polymorphism in the women group, which led us to use the result obtained in the random effects model denying the significant signal observed in the fixed effect model.

\section{Discussion}

In the present study, we screened the association of HNF1A gene with the MetS, through the genotyping of three of its polymorphisms (rs1169288, rs2464196 and rs735396) in a Tunisian case/control cohort.

The activity of the HNF1A transcription factor depends on three functional domains. Variations occurring within

Table 3 Characteristics of the studies included in the meta-analysis

\begin{tabular}{|c|c|c|c|c|c|c|c|c|c|c|c|c|c|}
\hline \multirow[t]{2}{*}{ Study } & \multirow[t]{2}{*}{ Population } & \multirow[t]{2}{*}{ Group } & \multirow[t]{2}{*}{ Subjects } & \multirow[t]{2}{*}{ Average age (years) } & \multicolumn{3}{|c|}{ rs1169288 } & \multicolumn{3}{|c|}{ rs2464196 } & \multicolumn{3}{|c|}{ rs735396 } \\
\hline & & & & & AA & $A C$ & $\mathrm{CC}$ & GG & GA & AA & TT & $\mathrm{TC}$ & $\mathrm{CC}$ \\
\hline \multirow[t]{2}{*}{ Morjane et al. (2017) } & Morocco & Controls & 137 & $50.6 \pm 10.34$ & 82 & 38 & 10 & 53 & 57 & 25 & 39 & 70 & 26 \\
\hline & & Cases & 104 & $57.59 \pm 11.57$ & 39 & 44 & 14 & 27 & 44 & 27 & 39 & 42 & 23 \\
\hline \multirow[t]{2}{*}{ Present study } & Tunisia & Controls & 299 & $52.56 \pm 10.09$ & 116 & 136 & 44 & 107 & 141 & 51 & 79 & 140 & 79 \\
\hline & & Cases & 295 & $56.4 \pm 8.50$ & 106 & 151 & 37 & 98 & 151 & 46 & 77 & 149 & 67 \\
\hline
\end{tabular}

Table 4 Results of meta-analysis using different genetic models

\begin{tabular}{|c|c|c|c|c|c|c|c|}
\hline \multirow[t]{2}{*}{ SNP } & \multirow[t]{2}{*}{ Genetic model } & \multicolumn{2}{|c|}{ Fixed effects model } & \multicolumn{2}{|c|}{ Random effects model } & \multicolumn{2}{|c|}{ Heterogeneity } \\
\hline & & OR $(95 \% \mathrm{Cl})$ & p-value & OR $(95 \% \mathrm{CI})$ & p-value & P-value & $\mathrm{I}^{2}(\%)$ \\
\hline rs1169288 & $A C$ vs $A A$ & $1.27(0.91-1.79)$ & 0.15 & $1.42(0.68-2.95)$ & 0.33 & 0.047 & 74.47 \\
\hline \multirow[t]{3}{*}{$A>C$} & CC vs AA & $1.14(0.68-1.90)$ & 0.61 & $1.36(0.46-3.99)$ & 0.57 & 0.058 & 72.16 \\
\hline & $A C+C C$ vs $A A$ & $1.26(0.91-1.73)$ & 0.14 & $1.43(0.64-3.20)$ & 0.37 & 0.018 & 81.88 \\
\hline & $C C$ vs $A C+A A$ & 1.01 (0.19-0.63) & 0.94 & $1.12(0.52-2.41)$ & 0.76 & 0.149 & 51.76 \\
\hline rs2464196 & GA vs GG & $1.21(0.85-1.71)$ & 0.28 & $1.28(0.75-2.18)$ & 0.35 & 0.164 & 48.13 \\
\hline \multirow[t]{3}{*}{$G>A$} & $A A$ vs $G G$ & $1.19(0.75-1.88)$ & 0.44 & $1.39(0.42-4.55)$ & 0.57 & 0.013 & 83.45 \\
\hline & $G A+A A v s G G$ & $1.19(0.86-1.66)$ & 0.28 & $1.35(0.65-2.82)$ & 0.41 & 0.042 & 75.65 \\
\hline & $A A$ vs $G A+G G$ & $1.07(0.71-1.61)$ & 0.73 & $1.16(0.49-2.78)$ & 0.72 & 0.039 & 76.52 \\
\hline rs735396 & TC vs TT & $0.84(0.58-1.21)$ & 0.35 & $0.82(0.52-1.28)$ & 0.39 & 0.234 & 29.18 \\
\hline \multirow[t]{3}{*}{$\mathrm{T}>\mathrm{C}$} & CC vs TT & $0.81(0.53-1.24)$ & 0.34 & $0.81(0.53-1.24)$ & 0.34 & 0.958 & 0 \\
\hline & $\mathrm{TC}+\mathrm{CC}$ vs TT & $0.83(0.59-1.63)$ & 0.28 & $0.83(0.59-1.16)$ & 0.28 & 0.389 & 0 \\
\hline & $\mathrm{CC}$ vs TC+TT & $0.89(0.61-1.67)$ & 0.53 & $0.89(0.61-1.27)$ & 0.53 & 0.548 & 0 \\
\hline
\end{tabular}

OR Odds ratio, $\mathrm{Cl}$ Confidence interval 
a Model

Morjane et al, 2017

Present study

Fixed

Random

\section{Study Population}

Morocco

Tunisia
OR $(95 \% \mathrm{CI})$

$2.82(1.42-5.60)$

$1.21(0.79-1.83)$

$1.53(1.06-2.20)$

$1.76(0.77-4.03)$ p-value

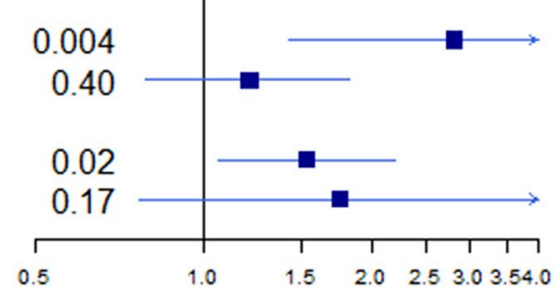

b Model

Study Population

OR $(95 \% \mathrm{Cl})$ p-value

Morjane et al, 2017

Morocco 3.06 (1.10-8.45)

Present study

Tunisia $0.82(0.43-1.54)$

Fixed

Random

$1.19(0.69-2.05)$

$1.48(0.41-5.37)$

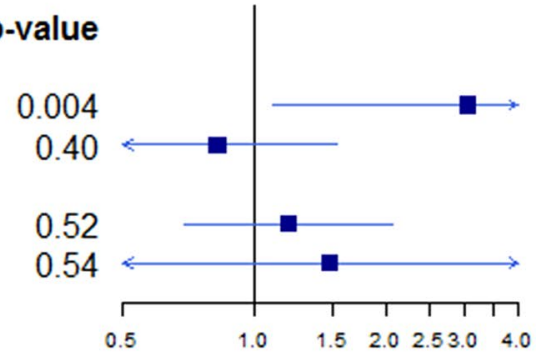

c

Model

Study name Population

OR $(95 \% \mathrm{Cl}) \quad p$-value

Morjane et al, 2017

Present study

Morocco 2.88 (1.52-5.44)

Tunisia $1.11(0.75-1.66)$

$1.44(1.03-2.01)$

Fixed

Random

$1.72(0.68-4.38)$

0.0009

0.60

0.03

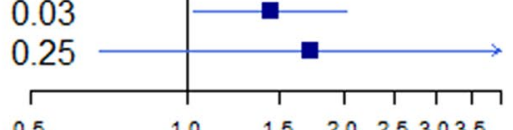

d

Model

Study name Population

OR $(95 \% \mathrm{Cl})$ p-value

Morjane et al, 2017

Present study

Morocco
Tunisia

$1.97(0.75-5.19)$

$0.74(0.41-1.33)$

Fixed

Random
$0.96(0.58-1.59)$

$1.11(0.43-2.88)$

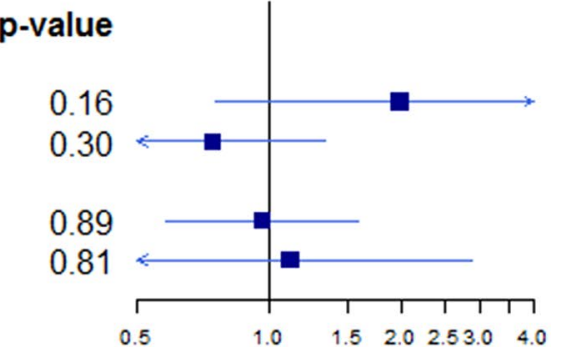

Fig. 2 Forest plots showing the meta-analysis results of the association between rs1169288 (A>C) and MetS in women. a Genetic model: AC vs AA, b Genetic model: CC vs AA, c Genetic model: AC + CC vs AA, d Genetic model: CC vs AA + AC. The forest plots were generated using "rmeta" $R$ library

these domains may have the biggest potential to alter its activity. The two missense genotyped variants rs1169288 and rs2464196 occur in the dimerization domain and the transactivation domain respectively. The third variant rs735396, occurring in intron 9, is localized in a transcription regulatory region [40]. The transactivation domain contains binding sites for other transcription coregulators that are important for the regulation of 
the target genes expression. The dimerization domain is responsible of the protein quaternary structure [41]. Hence, the combination of minor alleles of these three variants may have a major effect on HNF1A protein structure and function.

Our results showed no significant association of the genotyped SNPs with MetS in the studied sample even after stratification of the cohort following the sex and the geographic origin. The power analysis demonstrated that our study sample size (299 controls/295 cases) does not affect the detection of significant association. Indeed, we have previously identified significant associations of APOA5 polymorphisms with the MetS in two studies performed on the same cohort of the present work [26, 27].

To our knowledge, only two studies have investigated the association of HNF1A gene with MetS [23, 42]. Pollex et al., reported the association of the variant G319S with MetS in the Canadian Oji-Cree isolated population [42]. However, the investigation of this variant with MetS was not replicated in other populations. The three HNF1A gene variants (rs1169288, rs2464196 and rs735396) were selected on the basis of several previous studies reporting the association of these SNPs with T2D and cardiovascular diseases which are related to MetS as being a component or a complication [13-20]. Our finding is different from that observed in the study performed by Morjane et al. who reported that the variants rs 1169288 and rs2464196 in the HNF1A gene conferred an increased risk to MetS in a Moroccan population [23]. This difference may be explained by the heterogeneity of the populations' ethnic origins.

In the second part of our work, we investigated the association of the HNF1A gene variants (rs1169288, rs2464196 and rs735396) with MetS quantitative traits such as FPG, BMI, LDL, HDL, SBP, DBP, TG and WC in order to assess the involvement of these variants in the MetS components. Our results showed a significant association between the variant rs735396 and higher WC after Bonferroni correction, which is in agreement with Morjane et al. study [23]. This finding suggests that rs735396 may represent a genetic susceptibility to the obesity and can lead to the alteration of some metabolic and inflammatory pathways markers such as C-reactive protein levels, as it was mentioned in previous studies $[18,19]$. In this context, it is noteworthy to mention that obesity and altered CRP levels were associated with an increased risk for liver cancer [43, 44]. Furthermore, Jiang et al. had recently reported significant associations of this variant with the development of liver cancer, mainly through altering HNF1A gene expression in various stages of carcinogenesis. They suggested that rs735396, which is located in an enhancer regulatory region, might modulate HNF1A expression through affecting the temporal interaction between different trans-acting factors and the HNF1A enhancer [45]. Besides association with cancers, it was previously reported that elevation of CRP levels was associated with increased risk of ischemic stroke [46]. Therefore, effect of rs735396 on the susceptibility of ischemic stroke is worthwhile to be further investigated.

The stratified analysis, according to the sex, showed a strong association of rs1169288 genotypes with higher cholesterol levels only in the group of women. This result was not reported in the literature, and it may suggest the role of some sex-specific hormonal pathways, regulated by the HNF1A transcriptional machinery, in the metabolism of lipids. In this context, a recent study demonstrated that rs1169288 minor genotype is associated with an increased risk of preeclampsia, a pregnancy complication characterized by high blood pressure and signs of damage in liver [47]. Interestingly, Lee et al. reported an increased cholesterol biosynthesis and accumulation in the women with preeclampsia [48]. Subsequently, an in-depth investigation by Silva et al. demonstrated that inflammation intensification, resulting from an accumulation of cholesterol crystals, is the main pathway leading to preeclampsia [49]. Taking into account these points as well as the high expression of HNF1A in the liver, our findings may emphasize the potential impact of rs1169288 minor genotype in altering the cholesterol homeostasis in women. Accordingly, a previous study reported a sex-specific difference for the association of the FTO gene polymorphisms to MetS components in the Tunisian population [50].

Knowing that the genetic landscape of the Tunisian population is a mosaic due to successive invasions and migratory flows since the prehistoric period [51], we investigated the impact of the geographic origin on the genotype distribution of HNF1A variants (rs2464196, rs735396 and rs1169288). As a result, we did not find a significant association with MetS under any genotypic model neither for the Northern nor for the Southern region. In our previous study on the association of APOA5 gene variants with MetS, we emphasized an inter-regional variation within the Tunisian population since the variant rs651821 was significantly associated with MetS only for individuals originating from Northern Tunisia [26]. This is not the case for HNF1A variants. The sample size does not influence the result since the two studies were performed on the same Tunisian cohort.

When investigating the haplotype association with MetS quantitative traits, we found a significant association between the minor haplotype and higher cholesterol levels mainly in the women group. In this context, $\mathrm{Hu}$ et al. have recently demonstrated that HNF1A 
modulated the cholesterol homeostasis by activating the expression of microRNA-122 (miR-122), which is an abundant liver specific microRNA that regulates hepatocyte differentiation and proliferation as well as lipid metabolism. In addition, they found that loss of HNF1A function led to an abnormal cholesterol metabolism by altering HNF1A binding to miR-122 gene promotor and downregulating its expression [52]. Similarly, Huang et al. reported low circulating miR-122 levels in diabetic patients carrying HNF1A variants, and they suggested that this observation might partially explain the increased risk for abnormal lipid metabolism [53]. In this context, recent studies reported that serum miR-122 is associated with insulin resistance, obesity, and MetS [54, 55]. Therefore, these findings are in agreement with our results since the genotyped SNPs rs1169288 and rs2464196 are located within functional domains of the HNF1A protein, which may affect its binding to miR-122 promotor, resulting in the alteration of the cholesterol homeostasis. In another study, Zhou et al. have demonstrated that both rs1169288 and rs2464196 were significantly associated with serum lipid levels in controls as well as in coronary artery disease patients [24]. Indeed, Willer et al. found that genetic loci associated with cholesterol levels were also associated with the risk of coronary artery disease [56]. Furthermore, a genetic variant in $H N F 1 A$ was involved in a genetic score that is able to identify individuals at high risk of coronary heart disease, and with the largest relative and absolute clinical benefit with statin therapy, which is widely used for decreasing cholesterol levels [57]. Thus, our findings may potentially provide more insights into the study of the sex-specific biological pathways mediating lipid metabolism and involving HNF1A transcriptional machinery, which would identify potential therapeutic targets for the treatment of patients with lipid metabolism disorders. Particularly, it may be interesting to further explore the pathways affected by the statin treatment, and regulated by HNF1A. In fact, besides the effect of statin on reducing miR-122 serum levels, $\mathrm{Li}$ et al. have recently demonstrated that therapeutic targeting of a novel long noncoding RNA regulating HNF1A expression, might be an effective approach to enhance the effect of statin on cholesterol levels in clinics $[53,58]$.

Regarding the meta-analysis performed with the study carried in the Moroccan population, we did not find an association between the three HNF1A polymorphisms (rs1169288, rs2464196, rs735396) and the MetS. This result was expected for rs735396, since both studies have reported the same result. For the other two polymorphisms, although the study conducted in the
Moroccan population reported their association with MetS in codominant and dominant models, this outcome was denied when combined with our replication study conducted in the Tunisian population. To the best of our knowledge, this is the first meta-analysis of the association of HNF1A polymorphisms with MetS. In fact, published meta-analyses reported especially significant signals of HNF1A association with T2D and diabetes related serum biomarkers $[59,60]$. In North Africa, a previous meta-analysis grouping two studies from Morocco and Tunisia reported the association of one $H N F 1 A$ variant with $\mathrm{T} 2 \mathrm{D}$, and ruled out the association of another variant seen only in the Moroccan study, which is similar to the outcome of our meta-analysis [61].

Our study has some possible limitations. Firstly, although the power analysis demonstrated that the sample size does not affect the detection of a significant association, it is relatively small to provide sufficient power in order to confirm the non-association between MetS and HNF1A genetic variants. Secondly, the stratification of the sample according to the geographic origin further decreases statistical power. Thirdly, only two studies have investigated the association of the three HNF1A variants (rs1169288, rs2464196, rs735396) with MetS, which did not allow to gain a great statistical power in the meta-statistical analysis.

\section{Conclusions}

So far at the exception of two studies, no association studies have been conducted between HNF1A gene variants and MetS. Our results showed a significant association between the variant rs735396 and waist circumference and a significant association between the variant rs1169288 and high cholesterol level only in women. At haplotypic scale, a significant association was found between the minor haplotype and total cholesterol mainly in women. Our findings exclude the involvement of the three HNF1A variants rs1169288, rs2464196 and rs735396 in the susceptibility to MetS in Tunisia, but they emphasize the role of these polymorphisms in the metabolism of lipids with sex-specific differences. Nevertheless, due to the few number of studies, further case-control studies and meta-analyses are required in order to confirm the role of $H N F 1 A$ polymorphisms in the genetic predisposition to MetS.

\section{Abbreviations}

AIC: Akaike information criterion; BMI: Body mass index; Cl: Confidence interval; DBP: Diastolic blood pressure; FPG: Fasting plamsa glucose; GWAS: Genome-wide association studies; HDL: High-density lipoprotein; HNF1A: Hepatocyte Nuclear Factor 1 Alpha; HWE: Hardy Weinberg equilibrium; 
LD: Linkage disequilibrium; LDL: Low-density lipoprotein; MetS: Metabolic syndrome; miR: MicroRNA; OR: Odds ratio; SBP: Systolic blood pressure; SD: Standard deviation; SNPs: Single nucleotide polymorphisms; T2D: Type 2 diabetes; TG: Triglycerides; WC: Waist circumference.

\section{Supplementary Information}

The online version contains supplementary material available at https://doi. org/10.1186/s13098-022-00794-0.

Additional file 1: Table S1. Association of HNF1A genotypes with metabolic syndrome in the studied Tunisian population.

Additional file 2: Table S2. Genotypic distribution of HNF1A variants in the studied Tunisian population stratified according to the sex.

Additional file 3: Table S3. Genotypic distribution of HNF1A variants in the studied Tunisian population stratified following the geographic origin.

Additional file 4: Table S4. Genotypic distribution of HNF1A variants in the studied Tunisian population stratified following the sex and the geographic origin.

Additional file 5: Table S5. Association of HNF1A variants with metabolic syndrome traits for the Tunisian women in the study cohort.

Additional file 6: Table S6. Haplotype association analysis of the HNF1A variants with metabolic syndrome in the studied Tunisian population.

Additional file 7: Table S7. Haplotype analysis of the HNF1A variants with metabolic syndrome after stratification of the studied Tunisian population according to the sex.

Additional file 8: Table S8. Association of HNF1A minor haplotype CAC with metabolic syndrome traits in the studied Tunisian population.

Additional file 9: Table S9. Genotypic distribution of HNF1A variants in the Moroccan population stratified following the sex.

Additional file 10: Table S10. Results of meta-analysis using different genetic models in women.

\section{Acknowledgements}

We would like to thank the study participants for their collaboration. All authors belong to The MEDIGENE project, grant agreement number 279171, funded by the EC Seventh Framework Program theme FP7-HEALTH-2011.

\section{Authors' contributions}

Kefi and Abdelhak contributed to the design of the study. Dallali, Hechmi, Elouej, Jmel, Ben Halima, Morjane and Barakat contributed to the data collection. Abid and Jamoussi contributed to the clinical analysis. Bahlous contributed to the biochemical analyses. Dallali and Hechmi performed the experiments. Dallali performed the statistical analyses and drafted the manuscript. Kefi supervised all the analyses and edited the manuscript. Abdelhak reviewed the manuscript. All authors contributed to the manuscript revision and approved the submitted version.

\section{Funding}

This work was supported by the E.C. Grant agreement no. 279171-1 for FP7 project MEDIGENE and by the Tunisian Ministry of Public Health and the Ministry of Higher Education and Scientific Research (LR11IPT05).

\section{Availability of data and materials}

The datasets used and/or analysed during the current study are available from the corresponding author on reasonable request.

\section{Declarations}

\section{Ethics approval and consent to participate}

This study was approved by the Ethical committee of Institut Pasteur in Tunis (Reference IPT/LR1 1-05/Etude 04/2013). Informed consent was obtained from all the participants included in the study.

\section{Consent for publication}

Not applicable.

\section{Competing interests}

The authors declare that they have no competing interests.

\section{Author details}

${ }^{1}$ Laboratory of Biomedical Genomics and Oncogenetics, Institut Pasteur in Tunis, BP 74, 13 Place Pasteur, Belvedere, 1002 Tunis, Tunisia. ${ }^{2}$ University of Carthage, National Institute of Applied Science and Technology, Tunis, Tunisia. ${ }^{3}$ Human Molecular Genetics Laboratory, Institut Pasteur du Maroc, Place Louis Pasteur, Casablanca, Morocco. ${ }^{4}$ National Institute of Nutrition and Food Technology, 11 rue Jebel Lakhdar, Bab Saadoun, 1007 Tunis, Tunisia. ${ }^{5}$ Central Laboratory of Medical Biology, Institut Pasteur in Tunis, 13 Place Pasteur, BP 74, 1002 Tunis, Tunisia. ${ }^{6}$ University of Tunis El Manar, 2092 El Manar I Tunis, Tunisia.

Received: 20 October 2021 Accepted: 15 January 2022

Published online: 02 February 2022

\section{References}

1. Eckel RH, Grundy SM, Zimmet PZ. The metabolic syndrome. Lancet. 2005:365:1415-28.

2. Alberti KGMM, Eckel RH, Grundy SM, Zimmet PZ, Cleeman JI, Donato KA, et al. Harmonizing the Metabolic syndrome: a joint interim statement of the international diabetes federation task force on epidemiology and prevention; National Heart, Lung, and Blood Institute; American Heart Association; World Heart Federation. Int Circ. 2009;120:1640-5.

3. Grundy SM. Metabolic syndrome pandemic. Arterioscler Thromb Vasc Biol. 2008:28:629-36.

4. Belfki H, Ali SB, Aounallah-Skhiri H, Traissac P, Bougatef S, Maire B, et al. Prevalence and determinants of the metabolic syndrome among Tunisian adults: results of the Transition and Health Impact in North Africa (TAHINA) project. Public Health Nutr. 2013;16:582-90.

5. Park Y-W, Zhu S, Palaniappan L, Heshka S, Carnethon MR, Heymsfield SB. The metabolic syndrome: prevalence and associated risk factor findings in the US population from the Third National Health and Nutrition Examination Survey, 1988-1994. Arch Intern Med. 2003;163:427-36.

6. Liese AD, Mayer-Davis EJ, Tyroler HA, Davis CE, Keil U, Schmidt MI, et al. Familial components of the multiple metabolic syndrome: the ARIC Study. Diabetologia. 1997;40:963-70.

7. Chen W, Srinivasan SR, Elkasabany A, Berenson GS. The association of cardiovascular risk factor clustering related to insulin resistance syndrome (Syndrome X) between young parents and their offspring: the Bogalusa Heart Study. Atherosclerosis. 1999;145:197-205.

8. Jeong SW, Chung M, Park S-J, Cho SB, Hong K-W. Genome-Wide association study of metabolic syndrome in Koreans. Genomics Inf. 2014;12:187-94.

9. Avery $\mathrm{CL}, \mathrm{He} \mathrm{Q}$, North $\mathrm{KE}$, Ambite $\mathrm{L}$, Boerwinkle E, Fornage $\mathrm{M}$, et al. A Phenomics-based strategy identifies loci on APOC1, BRAP, and PLCG1 associated with metabolic syndrome phenotype domains. Gibson G, editor. PLoS Genet. 2011;7:e1002322.

10. Kathiresan S, Willer CJ, Peloso GM, Demissie S, Musunuru K, Schadt EE, et al. Common variants at 30 loci contribute to polygenic dyslipidemia. Nat Genet. 2009;41:56-65.

11. Odom DT, Zizlsperger N, Gordon DB, Bell GWGI, Rinaldi NJ, Murray HL, et al. Control of pancreas and liver gene expression by HNF transcription factors. Science (80-). 2004;303:1378-81.

12. Kavvoura FK, Owen KR. Maturity onset diabetes of the young: clinical characteristics, diagnosis and management. Pediatr Endocrinol Rev. 2012:10:234-42.

13. Weedon MN, Shields B, Hitman G, Walker M, McCarthy MI, Hattersley AT, et al. A large-scale association analysis of common variation of the HNF1alpha gene with type 2 diabetes in the U.K. Caucasian population. Diabetes. 2005;54:2487-91.

14. Voight BF, Scott LJ, Steinthorsdottir V, Morris AP, Dina C, Welch RP, et al. Twelve type 2 diabetes susceptibility loci identified through large-scale association analysis. Nat Genet. 2010;42:579-89.

15. Wakil SM, Muiya NP, Tahir Al, Al-Najai M, Baz B, Andres E, et al. A new susceptibility locus for myocardial infarction, hypertension, type 2 
diabetes mellitus, and dyslipidemia on chromosome 12q24. Dis Markers 2014;2014:291419.

16. Holmkvist J, Almgren P, Lyssenko V, Lindgren CM, Eriksson K-F, Isomaa B, et al. Common variants in maturity-onset diabetes of the young genes and future risk of type 2 diabetes. Diabetes. 2008:57:1738-44.

17. Reiner AP, Gross MD, Carlson CS, Bielinski SJ, Lange LA, Fornage M, et al. Common coding variants of the HNF1A gene are associated with multiple cardiovascular risk phenotypes in community-based samples of younger and older European-American adults: the Coronary Artery Risk Development in Young Adults study and the Cardiovascular Health Study. Circ Cardiovasc Genet. 2009;2:244-54.

18. Ridker PM, Pare G, Parker A, Zee RYL, Danik JS, Buring JE, et al. Loci related to metabolic-syndrome pathways including LEPR, HNF1A, IL6R, and GCKR associate with plasma C-reactive protein: the Women's Genome Health Study. Am J Hum Genet. 2008;82:1185-92.

19. Reiner AP, Barber MJ, Guan Y, Ridker PM, Lange LA, Chasman DI, et al. Polymorphisms of the HNF1A gene encoding hepatocyte nuclear factor-1a are associated with C-reactive protein. Am J Hum Genet. 2008;85(5):1193-201.

20. Holmkvist J, Cervin C, Lyssenko V, Winckler W, Anevski D, Cilio C, et al. Common variants in HNF-1 a and risk of type 2 diabetes. Diabetologia. 2006:49:2882-91

21. Li Y, Li L, Bi L, Xu X, Cheng W, Yu B, et al. Lipid-associated genetic polymorphisms are associated with FBP and LDL-c levels among myocardial infarction patients in Chinese population. Gene. 2018;676:22-8.

22. Zhang H, Mo X-B, XU T, Lei S-F, Zhang Y-H. Detecting novel genes for low-density lipoprotein cholesterol in European population using bioinformatics analysis. Per Med. 2016;13:225-31.

23. Morjane I, Kefi R, Charoute H, Lakbakbi el Yaagoubi F, Hechmi M, Saile $\mathrm{R}$, et al. Association study of HNF1A polymorphisms with metabolic syndrome in the Moroccan population. Diabetes Metab Syndr Clin Res Rev. 2017;11:S853-7.

24. Zhou Y-J, Yin R-X, Hong S-C, Yang Q, Cao X-L, Chen W-X. Association of the HNFIA polymorphisms and serum lipid traits, the risk of coronary artery disease and ischemic stroke. J Gene Med. 2017;19:e2941.

25. Grigorescu F. New genetic approaches in understanding susceptibility for metabolic syndrome in immigrant populations around mediterranean area. Acta Endocrinol. 2012;8:87-98.

26. Kefi R, Hechmi M, Dallali H, Elouej S, Jmel H, Ben Halima Y, et al. Association of apolipoprotein $\mathrm{A} 5$ gene variants with metabolic syndrome in Tunisian population. Ann Endocrinol (Paris). 2017;78:146-55.

27. Hechmi M, Dallali H, Gharbi M, Jmel H, Fassatoui M, BenHalima Y, et al. Association of rs662799 variant and APOA5 gene haplotypes with metabolic syndrome and its components: a meta-analysis in North Africa. Biosci Rep. 2020;40:BSR20200706.

28. Smith SM, Maughan PJ. SNP genotyping using KASPar assays. Methods Mol Biol. 2015;1245:243-56.

29. Dupont WD, Plummer WD. Power and sample size calculations for studies involving linear regression. Control Clin Trials. 1998;19:589-601.

30. Gonzalez JR, Armengol L, Sole X, Guino E, Mercader JM, Estivill X, et al. SNPassoc: an $R$ package to perform whole genome association studies. Bioinformatics. 2007;23:654-5.

31. Barrett JC, Fry B, Maller J, Daly MJ. Haploview: analysis and visualization of LD and haplotype maps. Bioinformatics. 2005;21:263-5.

32. Purcell S, Neale B, Todd-Brown K, Thomas L, Ferreira MAR, Bender D, et al. REPORT PLINK: a tool set for whole-genome association and population-based linkage analyses. Am J Hum Genet Am J Hum Genet. 2007;8181:559-75

33. Schaid DJ, Rowland CM, Tines DE, Jacobson RM, Poland GA. Score tests for association between traits and haplotypes when linkage phase is ambiguous. Am J Hum Genet. 2002;70:425-34.

34. Higgins JPT, Thompson SG. Quantifying heterogeneity in a meta-analysis. Stat Med. 2002;21:1539-58.

35. Mantel N, Haenszel W. Statistical aspects of the analysis of data from retrospective studies of disease. J Natl Cancer Inst. 1959;22:719-48.

36. DerSimonian R, Laird N. Meta-analysis in clinical trials. Control Clin Trials. 1986;7:177-88.

37. Mägi R, Morris AP. GWAMA: software for genome-wide association meta-analysis. BMC Bioinformatics. 2010;11:288.
38. Yuan RX, Zhang C, Luo L, Zeng XT, Niu YM. Performing metaanalysis using rmeta package in R software. Chin J Evid Based Med. 2015:15:735-40.

39. Viechtbauer W. Conducting meta-analyses in R with the metafor. J Stat Softw. 2010;36:1-48.

40. AMP T2D Knowledge Portal [Internet]. [cited 2020 Feb 2]. http://www. type2diabetesgenetics.org/variantlnfo/variantlnfo/rs735396

41. Awa WL, Thon A, Raile K, Grulich-Henn J, Meissner T, Schober E, et al. Genetic and clinical characteristics of patients with HNF1A gene variations from the German-Austrian DPV database. Eur J Endocrinol. 2011;164:513-20.

42. Pollex RL, Hanley AJG, Zinman B, Harris SB, Khan HMR, Hegele RA. Synergism between mutant HNF1A and the metabolic syndrome in Oji-Cree Type 2 diabetes. Diabet Med. 2005;22:1510-5.

43. Campbell PT, Newton CC, Freedman ND, Koshiol J, Alavanja MC, Freeman LEB, et al. Body mass index, waist circumference, diabetes, and risk of liver cancer for U.S. adults. Cancer Res. 2016;76:6076-83.

44. Chen W, Wang JB, Abnet CC, Dawsey SM, Fan JH, Yin LY, et al. Association between C-reactive protein, incident liver cancer, and chronic liver disease mortality in the linxian nutrition intervention trials: a nested case-control study. Cancer Epidemiol Biomarkers Prev. 2015;24:386-92.

45. Jiang M-M, Gu X, Yang J, Wang M-M, Li H-M, Fang M, et al. Association of a functional intronic polymorphism rs735396 in HNF1A gene with the susceptibility to hepatocellular carcinoma in Han Chinese population. Int J Clin Exp Pathol. 2017;10(1):671-9.

46. Liu Y, Wang J, Zhang L, Wang C, Wu J, Zhou Y, et al. Relationship between C-reactive protein and stroke: a large prospective community based study. Li Y, editor. PLoS One. 2014;9:e107017.

47. Beysel S, Pinarli FA, Eyerci N, Kizilgul M, Hepsen S, Alhan A, et al. HNF1A gene p.127L is associated with co-existing preeclampsia in gestational diabetes mellitus. Gynecol Endocrinol. 2020;36:530-4.

48. Lee SM, Moon JY, Lim BY, Kim SM, Park CW, Kim BJ, et al. Increased biosynthesis and accumulation of cholesterol in maternal plasma, but not amniotic fluid in pre-eclampsia. Sci Rep. 2019;9:1-8.

49. Silva GB, Gierman LM, Rakner JJ, Stødle GS, Mundal SB, Thaning AJ, et al. Cholesterol crystals and NLRP3 mediated inflammation in the uterine wall decidua in normal and preeclamptic pregnancies. Front Immunol. 2020;11:2478.

50. Elouej S, Nagara M, Attaoua R, Sallem OK, Rejeb I, Hsouna S, et al. Association of genetic variants in the FTO gene with metabolic syndrome: a case-control study in the Tunisian population. J Diabetes Complicat. 2016:30:206-11.

51. Kefi R, Hsouna S, Ben Halim N, Lasram K, Romdhane L, Messai H, et al. Phylogeny and genetic structure of Tunisians and their position within Mediterranean populations. Mitochondrial DNA. 2015;26:593-604.

52. Hu M, Huang $X$, Han X, Ji L. Loss of HNF1a function contributes to hepatocyte proliferation and abnormal cholesterol metabolism via downregulating miR-122: A novel mechanism of MODY3. Diabetes, Metab Syndr Obes Targets Ther. 2020;13:627-39.

53. Huang X, Gong S, Ma Y, Cai X, Zhou L, Luo Y, et al. Lower circulating miR-122 level in patients with HNF1A variant-induced diabetes compared with type 2 diabetes. J Diabetes Res. 2018;2018:1-6.

54. Willeit P, Skroblin P, Moschen AR, Yin X, Kaudewitz D, Zampetaki A, et al. Circulating MicroRNA-122 is associated with the risk of new-onset metabolic syndrome and type 2 diabetes. Diabetes. 2017;66:347-57.

55. Shah R, Murthy V, Pacold M, Danielson K, Tanriverdi K, Larson MG, et al. Extracellular RNAs are associated with insulin resistance and metabolic phenotypes. Diabetes Care. 2017;40:546-53.

56. Willer CJ, Sanna S, Jackson AU, Scuteri A, Bonnycastle LL, Clarke R, et al. Newly identified loci that influence lipid concentrations and risk of coronary artery disease. Nat Genet. 2008;40:161-9.

57. Mega JL, Stitziel NO, Smith JG, Chasman DI, Caulfield MJ, Devlin JJ, et al. Genetic risk, coronary heart disease events, and the clinical benefit of statin therapy: an analysis of primary and secondary prevention trials. Lancet. 2015;385:2264-71.

58. Li C, Hu Z, Zhang W, Yu J, Yang Y, Xu Z, et al. Regulation of cholesterol homeostasis by a novel long non-coding RNA LASER. Sci Rep. 2019:9:1-12. 
59. Ahluwalia TS, Allin KH, Sandholt CH, Sparsø TH, Jørgensen ME, Rowe M, et al. Discovery of coding genetic variants influencing diabetes-related serum biomarkers and their impact on risk of type 2 diabetes. J Clin Endocrinol Metab. 2015;100:E664-71.

60. Below JE, Gamazon ER, Morrison JV, Konkashbaev A, Pluzhnikov A, McKeigue PM, et al. Genome-wide association and meta-analysis in populations from Starr County, Texas, and Mexico City identify type 2 diabetes susceptibility loci and enrichment for expression quantitative trait loci in top signals. Diabetologia. 2011;54:2047-55.
61. Cauchi S, Ezzidi I, El Achhab Y, Mtiraoui N, Chaieb L, Salah D, et al. European genetic variants associated with type 2 diabetes in North African Arabs. Diabetes Metab. 2012:38:316-23.

\section{Publisher's Note}

Springer Nature remains neutral with regard to jurisdictional claims in published maps and institutional affiliations.
Ready to submit your research? Choose BMC and benefit from:

- fast, convenient online submission

- thorough peer review by experienced researchers in your field

- rapid publication on acceptance

- support for research data, including large and complex data types

- gold Open Access which fosters wider collaboration and increased citations

- maximum visibility for your research: over $100 \mathrm{M}$ website views per year

At BMC, research is always in progress.

Learn more biomedcentral.com/submissions 